\title{
Study of the Synergistic Effect of Nanoporous Nickel Phosphates on Novel Intumescent Flame Retardant Polypropylene Composites
}

\author{
Shibin Nie, ${ }^{1}$ Chi Zhang, ${ }^{1}$ Chao Peng, ${ }^{1}$ De-yi Wang, ${ }^{1,2}$ Daowei Ding, ${ }^{3}$ and Qingliang He ${ }^{3}$ \\ ${ }^{1}$ Key Laboratory of Safety and High Efficiency Coal Mining Ministry of Education, School of Mining and Safety Engineering, \\ Anhui University of Science and Technology, Huainan, Anhui 232001, China \\ ${ }^{2}$ IMDEA Materials Institute, C Eric Kandel 2, 28906 Madrid, Spain \\ ${ }^{3}$ Integrated Composites Laboratory (ICL), Dan F. Smith Department of Chemical Engineering, Lamar University, Beaumont, \\ TX 77710, USA
}

Correspondence should be addressed to Shibin Nie; nsb@mail.ustc.edu.cn and Qingliang He; qhe@lamar.edu

Received 29 October 2014; Revised 29 December 2014; Accepted 12 January 2015

Academic Editor: Luciano Bachmann

Copyright (C) 2015 Shibin Nie et al. This is an open access article distributed under the Creative Commons Attribution License, which permits unrestricted use, distribution, and reproduction in any medium, provided the original work is properly cited.

A char forming agent (CFA) and silica-gel microencapsulated ammonium polyphosphate (Si-MCAPP) were selected to form novel intumescent flame retardant system to prepare flame retardant polypropylene (PP) composites, and then the influences of nanoporous nickel phosphates $(\mathrm{NiP})$ on the thermal and flame retardant properties of flame retardant PP composites were studied by the real time FTIR (RTFTIR) spectra, limited oxygen index (LOI) test, and the scanning electron microscopy. RTFTIR shows the addition of $\mathrm{NiP}$ can improve the thermal stability of flame retardant PP composites. LOI test shows LOI value is increased with the increase of the content of $\mathrm{NiP}$, and the optimized concentration of NiP is $1.0 \%$. Furthermore, smoke toxicity of the novel flame retardant PP composites was studied by mice experiment. The upper limit of the no death smoke concentration of the composite is $12.37 \mathrm{mg} / \mathrm{L}$.

\section{Introduction}

As one of the most widely used polyolefin, polypropylene (PP) has applied to many fields such as architectural materials and cars. However, PP is combustible and releases smoke and poisonous gas with burning. The combustibility limits the range of its application fields. Therefore, it needs to make this plastic flame retardant [1]. The halogenated fire retardants synergizing with antimony trioxide are widely used for PP; however, halogenated flame retardants can release toxic gases and corrosive chemical fumes during burning. Thus, halogen-free flame retardants get more and more attention. Intumescent flame retardants are one of the effective halogenfree flame retardants (IFRs) [2, 3].

In previous work, CFA and silica-gel microencapsulated ammonium polyphosphate (Si-MCAPP) microencapsulated by $\mathrm{SiO}_{2}$ gel were used to form novel intumescent flame retardant system (IFRs) with better flame retardant and excellent water resistance properties. The influences of IFRs on thermal and flame retardancy properties of PP have been studied, and the results demonstrate the flame retardant PP composites with good flame retardant properties and excellent water resistance [4]. However, the flame retardant efficiency of IFRs still needs to be further improved compared to that of halogenated fire retardants.

Zeolites [5-7] and divalent or multivalent metallic compounds especially $\mathrm{Ni}$ compound [8-10] can improve the flame retardant behaviours of intumescent systems in polymer, but the efficiency of synergists still needs to be improved. Nanoporous nickel phosphate (NiP) has structure like zeolites with 24 polyhedra and $12 \mathrm{P}-\mathrm{OH}$ groups in each window of channels [11]. It has been demonstrated that NiP had an excellent synergistic effect with traditional intumescent flame retardants based on ammonium polyphosphate (APP) and pentaerythritol (PER) [12]. In the present work, the synergistic effect of nanoporous nickel phosphates $(\mathrm{NiP})$ on 
TABLE 1: Formulations of the flame retardant PP composites.

\begin{tabular}{lccc}
\hline Sample & PP & IFR $($ Si-MCAPP/CFA $=3: 1)$ & NiP \\
\hline PP0 & 70 & 30 & \\
PP1 & 70 & 29.5 & 0.5 \\
PP2 & 70 & 29 & 1.0 \\
PP3 & 70 & 28 & 2.0 \\
PP4 & 70 & 27 & 3.0 \\
\hline
\end{tabular}

the thermal and flame retardant properties of novel flame retardant PP composites was studied. Furthermore, smoke toxicity of the novel flame retardant PP composites was investigated by mice experiment.

\section{Experimental}

2.1. Materials. PP (homopolymer) was supplied as pellets by Yangzi Petrochemical Co. (China). CFA and Si-MCAPP were synthesized in our lab $[4,13]$. Nickel nitrate hexahydrate $\left(\mathrm{Ni}\left(\mathrm{NO}_{3}\right)_{2} \cdot 6 \mathrm{H}_{2} \mathrm{O}, 98.5 \%\right)$ was bought from Sinopharm Chemical Reagent Co. Ltd. Phosphoric acid $\left(\mathrm{H}_{3} \mathrm{PO}_{4}, 85 \%\right)$, $\mathrm{NH}_{4} \mathrm{~F}(96 \%)$, and ammonia were provided by Wuxi Zhanwang Chemical Reagent Co. Ltd. Mice aged 6-8 weeks were obtained from Anhui Medical University. Mice were maintained on a $12 \mathrm{~h}$ light/dark cycle at $22 \pm 2^{\circ} \mathrm{C}$ with food and water available.

2.1.1. The Synthesis of Nanoporous Nickel Phosphates NiP. $\mathrm{Ni}\left(\mathrm{NO}_{3}\right)_{2} \cdot 6 \mathrm{H}_{2} \mathrm{O}$ was dissolved with deionized water, and $\mathrm{H}_{3} \mathrm{PO}_{4}$ and $\mathrm{NH}_{4} \mathrm{~F}$ were added to the above solution. Then ammonia was dropped to adjust the $\mathrm{pH}$ to 2.5. Making the molar ratios of the mixture to be $1.0 \mathrm{Ni}\left(\mathrm{NO}_{3}\right)_{2}: 1.0 \mathrm{H}_{3} \mathrm{PO}_{4}: 1.0 \mathrm{NH}_{4} \mathrm{~F}: 40 \mathrm{H}_{2} \mathrm{O}$. All the above steps were done under vigorous stirring. The mixture was stirred for 0.5 hours and then sealed in Teflon-lined stainless steel autoclaves at $180^{\circ} \mathrm{C}$ for 4 days. Autoclaves were removed from the oven. The solid was obtained by filtering and then washed with plenteous deionized water at room temperature and dried at $80^{\circ} \mathrm{C}$ for $12 \mathrm{~h}$.

2.1.2. The Preparation of Samples. PP, Si-MCAPP, CFA, and $\mathrm{NiP}$ were dried in vacuum oven at $80^{\circ} \mathrm{C}$ before use. Then PP, $\mathrm{Si}$-MCAPP, CFA, and NiP were melt-mixed in a twin-roller mill (XSS-300, China) for $10 \mathrm{~min}$. The temperature of the mill was maintained at $175^{\circ} \mathrm{C}$ and the roller speed was $60 \mathrm{rpm}$. The samples are listed in Table 1 . The resulting composites were hot-pressed into sheets with suitable thickness and size for LOI tests.

2.2. Smoke Toxicity Experiment [14]. In the experiment the sample is heated stably by YD-1 smoke toxicity test device (Figure 1) using the hoop-stove by scanning way. The carrier gas is uniform, and the hoop-stove is moving at a constant speed. The mice experiment is carried out when the smoke was generated fully.

(1) Weigh and cage the mice according to the serial number and place them in the infected box on the stents $5 \mathrm{~min}$ ago before the test and then cover the box lid and adjust the dilution gas to the design flow rate and next regulate the hoop-stove temperature up to the required temperature.

(2) Put the sample in the quartz boat $20 \mathrm{~mm}$ away from the front of the hoop-stove and run the hoop-stove at the set speed for scanning heating.

(3) Start timing when the hoop-stove runs to the tip of the sample and then open the three-way cock to release the smoke directly that is generated in the initial $10 \mathrm{~min}$. In the following rotate the three-way cock to allow the mixture of the smoke and the diluting gas to flow into the infected box; then the test begins.

(4) Observe and record the behavior changes of the mice during the 30 min test.

(5) Rotate the three-way cock and drain off the residual gas directly after $30 \mathrm{~min}$. At the moment open the infected box quickly and take out the mice.

(6) Run the hoop-stove over the sample, stop heating and remove the sample residue, and cool, weight, and calculate the smoke production rate of the material.

2.3. Calculation. The calculation of the smoke concentration

$$
C=\frac{V M}{F L},
$$

where $C$ is the smoke concentration, $\mathrm{mg} / \mathrm{L}, V$ is the movement rate of the hoop-stove, $10 \mathrm{~mm} / \mathrm{min}, M$ is sample quality, $\mathrm{mg}, F$ is smoke flow, $\mathrm{L} / \mathrm{min}$, and $L$ is the length of the sample, $\mathrm{mm}$.

The test lasts for $30 \mathrm{~min}$, and the sample length is $400 \mathrm{~mm}$.

Smoke flow is composed of carrier gas flow and dilution air flow

$$
F=F 1+F 2 .
$$

where $F$ is smoke flow, $\mathrm{L} / \mathrm{min}, F 1$ is carrier gas flow, $\mathrm{L} / \mathrm{min}$, and $F 2$ is dilution air flow, $\mathrm{L} / \mathrm{min}$.

In general, the carrier gas flow rate is $5 \mathrm{~L} / \mathrm{min}$ as a priority; when the smoke flow $F \leq 5 \mathrm{~L} / \mathrm{min}$, then $F=F 1, F 2=0$.

2.4. Characterization. LOI was measured according to ASTM D2863, and the apparatus used was an HC-2 oxygen index meter (Jiangning Analysis Instrument Company, China). The specimens dimensions used for test were $100 \times 6.5 \times 3 \mathrm{~mm}^{3}$.

The real time FTIR (RTFTIR) spectra were recorded using a Nicolet MAGNA-IR750 spectrometer equipped with a heating device and a temperature controller. The temperature of the oven was raised at a heating rate of about $10^{\circ} \mathrm{C} / \mathrm{min}$.

The scanning electronmicroscopy (SEM) image of the residue after the LOI test was taken using a KYKY-2800B scanning electron microscope produced by Zhongke Keyi Company. The char was put on the copperplate and then coated with gold/palladium alloy ready for imaging.

YD-1 smoke toxicity test device (Jiangning Analysis Instrument Company, China) is used to measure the smoke toxicity level of the materials.

\section{Results and Discussion}

3.1. Characterization of the NiP. The FTIR spectrum of NiP is shown in Figure 2. The spectrum exhibits relatively sharp 


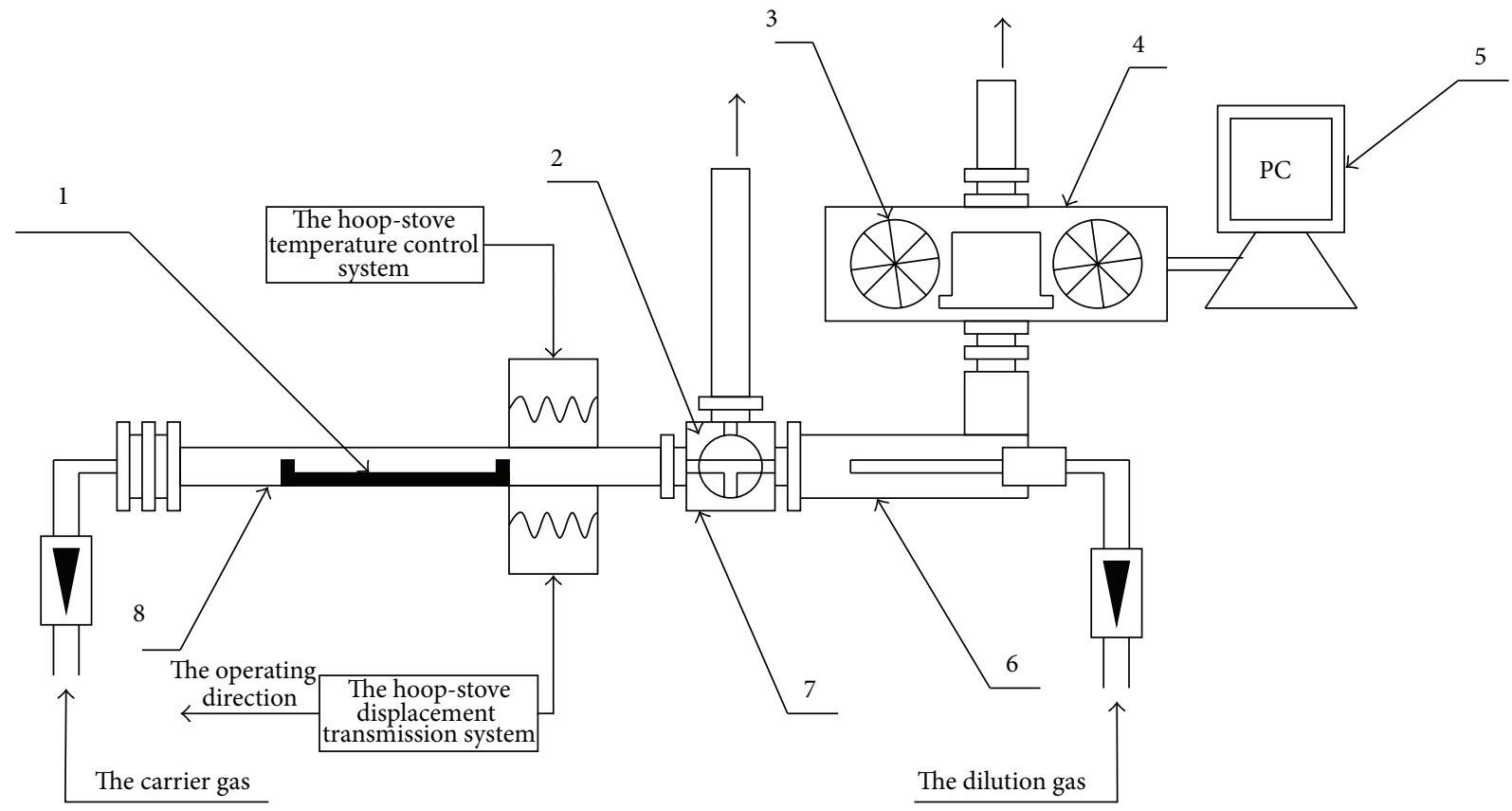

Figure 1: The schematic diagram of the smoke toxicity test device: 1 . the quartz boat, 2 . the three-way cock, 3 . the infected box, 4 . the mouse cage, 5. computer, 6 . the gas distribution pipe bending, 7. the hoop-stove, and 8. the quartz tube.

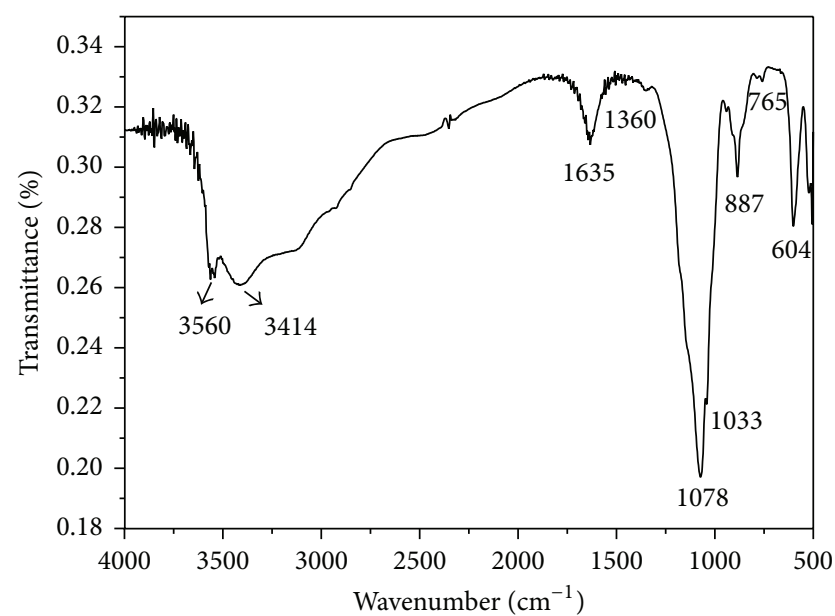

FIgURE 2: The FTIR spectrum of NiP.

peak at $3560 \mathrm{~cm}^{-1}$ and a broad band at $3414 \mathrm{~cm}^{-1}$. The peak at $3560 \mathrm{~cm}^{-1}$ is due to isolated $\mathrm{OH}$ groups, and the $\mathrm{O}-\mathrm{H}$ bending vibration of $\mathrm{H}_{2} \mathrm{O}$ can be found at $1640 \mathrm{~cm}^{-1}$. The broad band around 3414 is attributed to the overlap between hydrogen-bonded $\mathrm{OH}$ groups and hydrogen-bonded ammonium ions or adsorbed water/hydronium ions in the channels [15]. The asymmetrical stretching vibration of $\mathrm{P}-\mathrm{O}$ appears at 1078 and $1033 \mathrm{~cm}^{-1}$. The symmetrical stretching vibration of $\mathrm{P}-\mathrm{O}$ is detected at $887 \mathrm{~cm}^{-1}$. The bending vibration of $\mathrm{P}-\mathrm{O}$ can be observed at 765 and $604 \mathrm{~cm}^{-1}$.

XRD pattern of NiP is shown in Figure 3. The diffraction peaks are sharp, which show the synthetic material has good crystallinity. Diffraction peak at a small angle in $2 \theta$ means

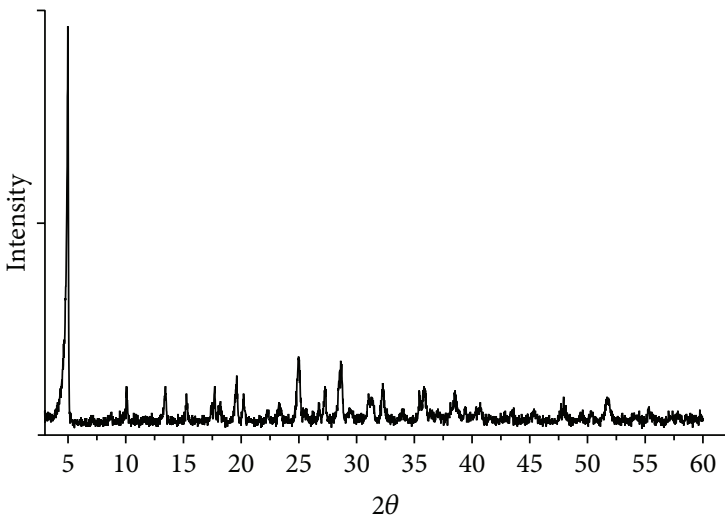

FIgure 3: The XRD pattern of NiP.

the unit cell parameters is high, meaning the framework structure inner may be more open. The position of diffraction peaks appearing in Figure 3 is just like the report in the literature [11], demonstrating the synthesis of NiP. Figure 4 is the scanning electron microscope photo of $\mathrm{NiP}$ with 300 times magnified. $\mathrm{NiP}$ has a sharp needle-shaped morphology. Almost all particles are usually gathered together, forming just like the mushroom shape.

The TGA curve of the NiP is shown in Figure 5. The thermal weight loss process of $\mathrm{NiP}$ can be divided into three stages-30 250 $0^{\circ} \mathrm{C}, 250 \sim 450^{\circ} \mathrm{C}$, and $450 \sim 700^{\circ} \mathrm{C}$. The first stage before $250^{\circ} \mathrm{C}$ is mainly water weight loss, and the weight loss rate is $9.1 \mathrm{wt} \%$. From $250^{\circ} \mathrm{C}$ to $450^{\circ} \mathrm{C}$ the main losses are the hydroxyl and amino groups, and the weight loss rate is $11.7 \mathrm{wt} \%$ at $450^{\circ} \mathrm{C}$. When the temperature is over $700^{\circ} \mathrm{C}$, 


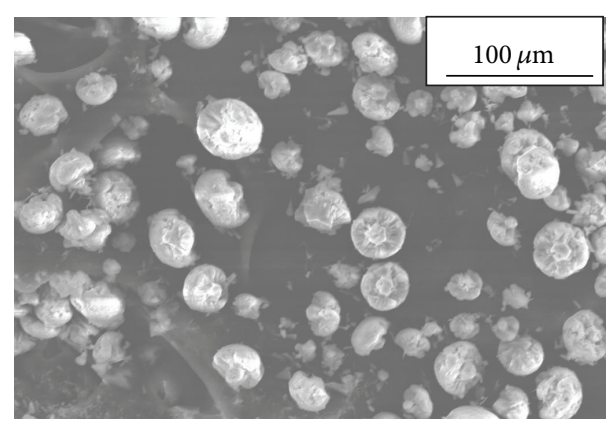

FIgURE 4: The SEM photograph of NiP.

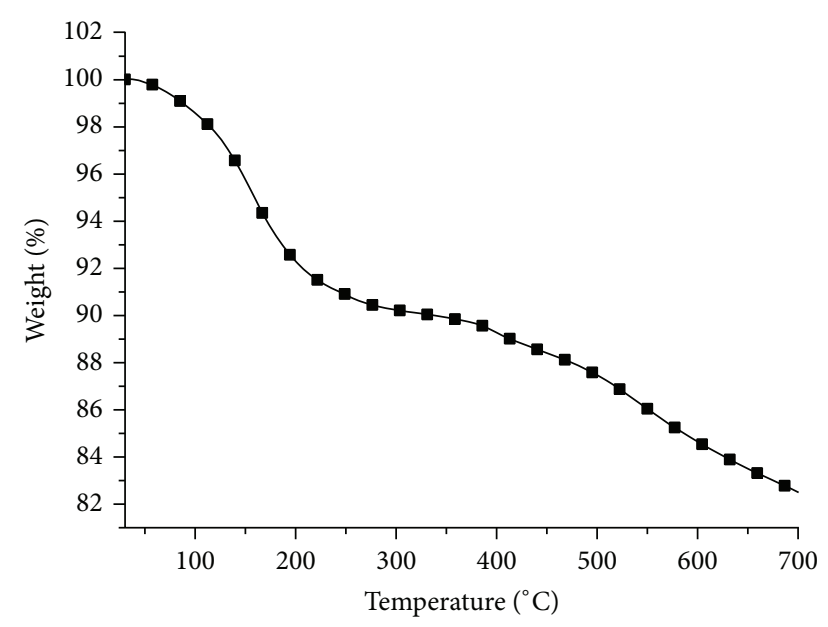

Figure 5: The TGA curve of NiP.

the weight loss rate is $17.5 \mathrm{wt} \%$, and there is still $82.5 \mathrm{wt} \%$ of the residue remaining [11].

3.2. LOI Analysis. The LOI results of flame retardant PP composites are shown in Figure 6. PP is highly combustible, and the LOI value is just $17.5 \%$. It can be observed from Figure 6 that the LOI value of PP0 without NiP is $40.0 \%$. Keeping the total amount of additives as $30 \mathrm{wt} \%$ unchanging, with the addition of $0.5 \mathrm{wt} \% \mathrm{NiP}$, the LOI value of PP1 is $41.5 \%$. LOI value is increased with the increase of the content of $\mathrm{NiP}$ and reaches a maximum value, and then the value will decrease with increase of the content of $\mathrm{NiP}$. The highest LOI value is $42.5 \%$ with the addition of $1.0 \mathrm{wt} \%$ $\mathrm{NiP}$ (PP2). NiP can decrease the flame retardant behaviors of PP composites with higher content. With the addition of $3.0 \mathrm{wt} \% \mathrm{NiP}$, the LOI value decreases to $37.5 \%$. It can be concluded that $\mathrm{NiP}$ with the suitable content can improve the flame retardant properties of the PP composites, and the higher content decreases the synergistic effect. It can be explained that nickel phosphates can be a catalyst for ammonium polyphosphate to form bridges between two phosphate groups, which makes more phosphorous compound available for the phosphorylation. However, nickel phosphates with high content crosslink ammonium polyphosphate chains by the salt bridges and decrease the mobility of ammonium



FIgURE 6: The LOI curve of flame retardant PP composites.

polyphosphate chains. This is equivalent to removing part of ammonium polyphosphate from systems, so the flame retardancy of the PP composite decreases with high content of $\mathrm{NiP}[12]$.

3.3. Analysis of RTFTIR. RTFTIR spectra of flame retardant $\mathrm{PP}$ composites are shown in Figure 7. The asymmetric and symmetric vibration peaks of the $\mathrm{CH}_{2}$ or $\mathrm{CH}_{3}$ can be found at 2962 and $2920 \mathrm{~cm}^{-1}$ and the deformation vibration one appears at 1460 and $1380 \mathrm{~cm}^{-1}$ [15]. With the temperature increasing, the intensity of these peaks decreases due to the decomposition of the PP. The stretching vibration peaks of $\mathrm{N}-\mathrm{H}$ and $\mathrm{O}-\mathrm{H}$ are at $3500 \mathrm{~cm}^{-1} \sim 3200 \mathrm{~cm}^{-1}$. Above $280^{\circ} \mathrm{C}$, all of $\mathrm{N}-\mathrm{H}$ and $\mathrm{O}-\mathrm{H}$ peaks' strength become weak mainly because of the dehydration reaction and deamination reaction in system [16]. The $\mathrm{P}=\mathrm{O}$ stretching vibration peak at $1257 \mathrm{~cm}^{-1}$ shifts to the high position; this is because with the dehydration reaction reacting, the effect of hydroxyl bond gradually becomes weak. The symmetric stretching vibration peak of $\mathrm{P}-\mathrm{O}$ is at $1100 \mathrm{~cm}^{-1}$, while the position of the peak gradually moves to the low band with the pyrolysis temperature increasing; this is mainly because the $\mathrm{P}-\mathrm{O}-\mathrm{C}$ bond changes into $\mathrm{P}-\mathrm{O}-\mathrm{P}$ bond $[17,18]$. The absorption peaks at $970 \mathrm{~cm}^{-1}$ and $880 \mathrm{~cm}^{-1}$ belong to phosphorus oxygen compounds. In the flame retardant PP composites $\mathrm{Si}-\mathrm{O}$ absorption peak is not obvious due to the overlap of position of the absorption peak of $\mathrm{Si}-\mathrm{O}$ and $\mathrm{P}-\mathrm{O}$. At $350^{\circ} \mathrm{C}$, there are new vibration peaks corresponding to the crosslinked aromatic ring structure containing $\mathrm{P}-\mathrm{O}$ bond and $\mathrm{Si}-\mathrm{O}$ bond they appear at $756 \mathrm{~cm}^{-1}$ and $670 \mathrm{~cm}^{-1}$, so the $\mathrm{Si}-\mathrm{O}-\mathrm{Si}$ and $\mathrm{P}-\mathrm{O}-\mathrm{P}$ cross-linked structure is built in the carbon layer [19]. It was also observed from Figure 7(a) that all peaks around $2900 \mathrm{~cm}^{-1}$ almost disappear at $380^{\circ} \mathrm{C}$, demonstrating the complete decomposition of PP. On the other hand, with the addition of $1.0 \mathrm{wt} \% \mathrm{NiP}$ (Figure 7(b)), these peaks still appear at $420^{\circ} \mathrm{C}$. It can thus be concluded that the thermal stability of flame retardant PP composites was enhanced with the addition of the NiP. 


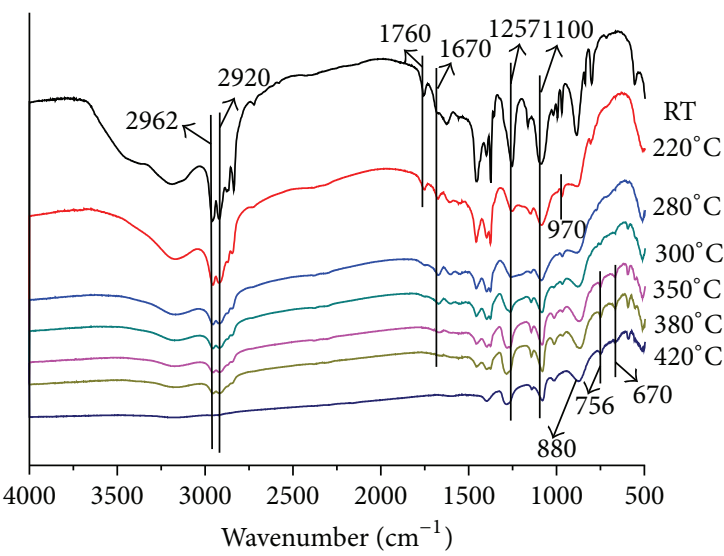

(a)

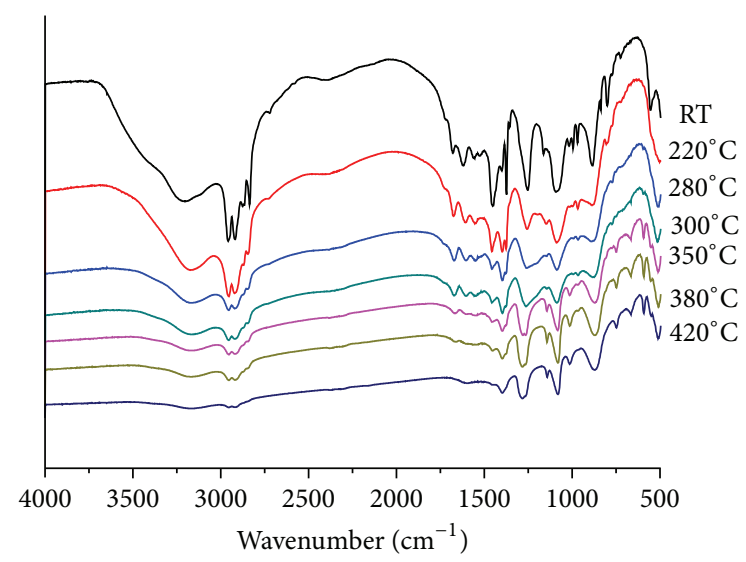

(b)

FIgURE 7: RTFTIR spectra at different pyrolysis temperature: (a) PP0, (b) PP2.



(a)



(b)

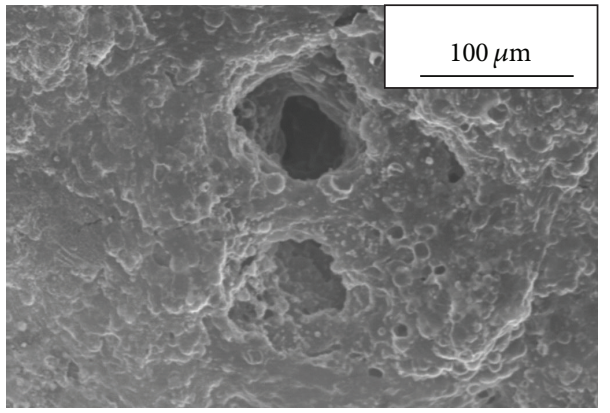

(c)

FIGURE 8: SEM photographs of outer char surface after LOI test: (a) PP0, (b) PP2, and (c) PP4.

3.4. Analysis of the Morphology of the Residual Char. The scanning electron microscopy was used to further study the morphology of the residual char obtained after LOI test (Figure 8). The study of the morphology of the char can is useful to explain the differences in the flame retardant behaviors among the different flame retardant PP composites. The image of outer char layer of the PP0 composite is shown in Figure 8(a). The coherent and dense char layer is formed and effectively prevents transference of the heat between the flame zone and the matrix. Thus it inhibits the underlying matrix from further burning. Figure $8(\mathrm{~b})$ shows the image of the outer char of the PP2 composite. With the addition of $1.0 \mathrm{wt} \% \mathrm{NiP}$, the outer surface of char residue shows more compacted form. Char residue stacks together to form "hills" with larger thickness. This char layer is less susceptible to crack during the high temperature and is more effective to prevent the transfer of the heat and combustible gases during burning. The char layer of the PP 4 with the addition of $3 \mathrm{wt} \%$ NiP (Figure $8(\mathrm{c})$ ) presents some large holes, and these large holes may weaken the protective effect of char layer. So the flame retardant ability of PP4 is not as good as that of PP2.

\subsection{Smoke Toxicity Analysis}

3.5.1. The Choosing of Experimental Concentration. Select the smoke concentration from the range of $1.15^{n} \mathrm{mg} / \mathrm{L}$ 
$(n=0,1,2,3, \ldots)$ which would produce the effect. For example,

$$
\begin{aligned}
& 6.15 \mathrm{mg} / \mathrm{L}(n=13) ; 12.4 \mathrm{mg} / \mathrm{L}(n=18) ; 24.9 \mathrm{mg} / \mathrm{L} \\
& (n=23) ; \\
& 50.0 \mathrm{mg} / \mathrm{L}(n=28) ; 76.1 \mathrm{mg} / \mathrm{L}(n=31) ; 101.7 \mathrm{mg} / \mathrm{L} \\
& (n=33) .
\end{aligned}
$$

Change the $n$ values of $1.15^{n}$ to adjust the smoke concentration according to the selected experiment results. For example, take the smoke concentration of $1.15^{n} \mathrm{mg} / \mathrm{L}$ and $1.15^{n+1} \mathrm{mg} / \mathrm{L}$ to carry out the mice experiment, if there is no mice death at the $1.15^{n} \mathrm{mg} / \mathrm{L}$, but there are some deaths at $1.15^{n+1} \mathrm{mg} / \mathrm{L}$; then consider the $1.15^{n} \mathrm{mg} / \mathrm{L}$ as the upper limit of the no death smoke concentration $\left(\mathrm{LC}_{0}\right)$.

3.5.2. The Choosing of Experimental Temperature. In this experiment intumescent flame retardant PP composite (PP2, $1.0 \mathrm{wt} \% \mathrm{NiP}$ ) with the best flame retardant performance was used to study the smoke toxicity. Firstly the heating temperature should be determined. $300^{\circ} \mathrm{C}, 400^{\circ} \mathrm{C}, 500^{\circ} \mathrm{C}$, and $600^{\circ} \mathrm{C}$ are selected as the heating temperature. The experiment shows that at $400^{\circ} \mathrm{C}$ the sample is under flameless combustion, and above $400^{\circ} \mathrm{C}$ the sample is under flame combustion. Because part of the pyrolysis products is fully burned at high temperature under flame combustion, the smoke and poisonous products are relatively less and show low toxicity when compared with the insufficient flameless combustion situation. In this work $400^{\circ} \mathrm{C}$ is chosen as the experimental temperature for smoke toxicity analysis.

3.6. Smoke Toxicity Analysis. The smoke concentration of $28.57 \mathrm{mg} / \mathrm{L}$ is selected as the experiment smoke concentration firstly. According to formula (1), it can be calculated that the required quality of materials is $5714.9 \mathrm{mg}$. During toxic experiment the mice show seeking refuge, behavior anomaly on eye and respiration, and increasing mucus in mouth and nose. After 8 minutes, the mice begin to appear the symptoms such as eyes closing, tear, accelerated breath, and cough, and part of mice cannot walk naturally. At 25 minutes the mouse numbers 3 and 5 die, at 29 minutes mouse numbers 2, 4, 8, and 9 die, and at 29.5 minutes mouse numbers 1 and 6 die. In the 30-minute toxic experiment, all of the mice are killed. From the above results, the smoke toxicity is serious when the smoke concentration is $28.57 \mathrm{mg} / \mathrm{L}$ under the $400^{\circ} \mathrm{C}$ heating temperature. To explore the upper limit of the no death smoke concentration the smoke concentration should be continued to reduce.

Choosing $14.23 \mathrm{mg} / \mathrm{L}$ as the smoke concentration and according to the formula (1), it can be calculated that the required quality of the sample is $2846.0 \mathrm{mg}$. During the experiment mice show some symptoms such as smoke movement, seeking refuge, behavior anomaly in ocular, and respiration. Eight minutes later the mouse numbers 1, 3, 4, 6, and 9 show the phenomenon of eyes closed and intermittent motion. After 11 minutes, all the mice close eyes accompanied by accelerated respiration. From 15 to 30 minutes during experiment all the mice become inactive. The mouse number 9 loses balance and cannot walk naturally after 20 minutes.
Finally, mouse number 9 dies in 28 minutes. During the experiment for 30 minutes, one of eight mice dies. The surviving mice have no death within $1 \mathrm{~h}$ after the experiment but are weak and anorectic. The average weight of survived mice recovers the weight within 3 days.

Choosing $12.37 \mathrm{mg} / \mathrm{L}$ as the smoke concentration and according to formula (1), it can be calculated that the required quality of the sample is $2474.0 \mathrm{mg}$. Eight minutes later mouse numbers 2, 5, 8, and 9 show closed eyes and intermittent motion. After 14 minutes, all the mice close eyes accompanied by accelerated respiration. From 15 to 30 minutes, all of the mice become inactive. In the 30 minutes of the experiment and the following 1 hour within the experiment, all of the mice survive. The surviving mice become weak and anorectic, and recover to the weight in the following 3 days. From the above results it can be known that the upper limit of the no death smoke concentration is $12.37 \mathrm{mg} / \mathrm{L}$.

\section{Conclusions}

The addition of suitable content of NiP can improve the flame retardant properties of $\mathrm{PP}$ composites, and the optimized concentration of $\mathrm{NiP}$ is $1.0 \%$. With the addition of $1.0 \mathrm{wt} \%$ $\mathrm{NiP}$, the LOI value of flame retardant PP increases from $40.0 \%$ to $42.5 \%$. Furthermore, NiP with suitable content can improve the thermal stability and strengthen the char layer of flame retardant PP composite and effectively prevent transference of the heat between the flame zone and the matrix, protecting the underlying matrix from further burning. Smoke toxicity analysis based on mice experiment shows that the upper limit of the no death smoke concentration of the flame retardant PP composite with the best flame retardancy is $12.37 \mathrm{mg} / \mathrm{L}$. The synergy of NiP with novel intumescent flame retardants is hoped to provide a promising way for the design new efficient intumescent materials with low smoke toxicity.

\section{Conflict of Interests}

The authors declare that there is no conflict of interests regarding the publication of this paper.

\section{Acknowledgments}

The work was financially supported by National Natural Science Foundation of China (no. 51303004, U1332134), the Specialized Research Fund for the Doctoral Program of Higher Education of China (no. 20133415120001), the Revitalization Plan of Anhui Province and Anhui Province Center of Collaborative Innovation for City Public Security.

\section{References}

[1] Y. Liu, J. Yi, and X. Cai, “The investigation of intumescent flameretarded polypropylene using poly(hexamethylene terephthalamide) as carbonization agent," Journal of Thermal Analysis and Calorimetry, vol. 107, no. 3, pp. 1191-1197, 2012.

[2] H. L. Vandersall, "Intumescent coating systems, their development and chemistry," Journal of Fire and Flammability, vol. 1, no. 2, pp. 97-140, 1970. 
[3] G. Camino, L. Costa, L. Trossarelli, F. Costanzi, and A. Pagliari, "Study of the mechanism of intumescence in fire retardant polymers: part VI-Mechanism of ester formation in ammonium polyphosphate-pentaerythritol mixtures," Polymer Degradation and Stability, vol. 12, no. 3, pp. 213-228, 1985.

[4] S. Nie, C. Peng, S. Yuan, and M. Zhang, "Thermal and flame retardant properties of novel intumescent flame retardant polypropylene composites," Journal of Thermal Analysis and Calorimetry, vol. 113, no. 2, pp. 865-871, 2013.

[5] S. B. Nie, S. H. Qi, M. S. He, and B. Li, "Synergistic effects of zeolites on a novel intumescent flame-retardant low-density polyethylene (LDPE) system," Journal of Thermal Analysis and Calorimetry, vol. 114, no. 2, pp. 581-587, 2013.

[6] C. M. Feng, Y. Zhang, S. W. Liu, Z. Chi, and J. Xu, "Synergistic effects of $4 \mathrm{~A}$ zeolite on the flame retardant properties and thermal stability of a novel halogen-free PP/IFR composite," Polymers for Advanced Technologies, vol. 24, no. 5, pp. 478-486, 2013.

[7] S. Bourbigot, M. Le Bras, R. Delobel, and J.-M. Trémillon, "Synergistic effect of zeolite in an intumescence process: study of the interactions between the polymer and the additives," Journal of the Chemical Society: Faraday Transactions, vol. 92, no. 18, pp. 3435-3444, 1996.

[8] K. Q. Zhou, S. H. Jiang, B. B. Wang et al., "Combined effect of transition metal phosphide $\left(\mathrm{M}_{x} \mathrm{P}_{y}, \mathrm{M}=\mathrm{Ni}, \mathrm{Co}\right.$, and $\left.\mathrm{Cu}\right)$ and intumescent flame retardant system on polypropylene," Polymers for Advanced Technologies, vol. 25, no. 7, pp. 701-710, 2014.

[9] D. Liu, G. Cai, J. Wang et al., "Thermal and flammability performance of polypropylene composites containing melamine and melamine phosphate-modified $\alpha$-type zirconium phosphates," Journal of Applied Polymer Science, vol. 131, no. 10, Article ID 40254, 2014.

[10] M. Lewin and M. Endo, "Catalysis of intumescent flame retardancy of polypropylene by metallic compounds," Polymers for Advanced Technologies, vol. 14, no. 1, pp. 3-11, 2003.

[11] N. Guillou, Q. Gao, M. Nogues et al., "Zeolitic and magnetic properties of a 24-membered ring porous nickel(II) phosphate, VSB-1," Comptes Rendus de l'Academie des Sciences-Series IIC: Chemistry, vol. 2, no. 7-8, pp. 387-392, 1999.

[12] S. Nie, Y. Hu, L. Song, S. He, and D. Yang, "Study on a novel and efficient flame retardant synergist-nanoporous nickel phosphates VSB-1 with intumescent flame retardants in polypropylene," Polymers for Advanced Technologies, vol. 19, no. 6, pp. 489-495, 2008.

[13] S. Nie, Y. Hu, L. Song, Q. He, D. Yang, and H. Chen, "Synergistic effect between a char forming agent (CFA) and microencapsulated ammonium polyphosphate on the thermal and flame retardant properties of polypropylene," Polymers for Advanced Technologies, vol. 19, no. 8, pp. 1077-1083, 2008.

[14] “Toxic classification of fire effluents hazard for materials," Tech. Rep. GB/T20285-2006, 2006.

[15] S. Bourbigot, M. Le Bras, R. Delobel, P. Bréant, and J.M. Trémillon, "Carbonization mechanisms resulting from intumescence-part II. Association with an ethylene terpolymer and the ammonium polyphosphate-pentaerythritol fire retardant system," Carbon, vol. 33, no. 3, pp. 283-294, 1995.

[16] G. Camino, L. Costa, L. Trossarelli, F. Costanzi, and G. Landoni, "Study of the mechanism of intumescence in fire retardant polymers: part IV_evidence of ester formation in ammonium polyphosphate-pentaerythritol mixtures," Polymer Degradation and Stability, vol. 8, no. 1, pp. 13-22, 1984.
[17] S. V. Levchik, G. Camino, L. Costa, and G. F. Levchik, "Mechanism of action of phosphorus-based flame retardants in nylon 6. I. Ammonium polyphosphate," Fire and Materials, vol. 19, no. 1, pp. 1-10, 1995.

[18] M. Bugajny, S. Bourbigot, M. le Bras, and R. Delobel, “The origin and nature of flame retardance in ethylene-vinyl acetate copolymers containing hostaflam AP 750," Polymer International, vol. 48, no. 4, pp. 264-270, 1999.

[19] B. B. Wang, Q. L. Tai, S. B. Nie et al., "Electron beam irradiation cross linking of halogen-free flame-retardant ethylene vinyl acetate (EVA) copolymer by silica gel microencapsulated ammonium polyphosphate and char-forming agent," Industrial and Engineering Chemistry Research, vol. 50, no. 9, pp. 5596$5605,2011$. 

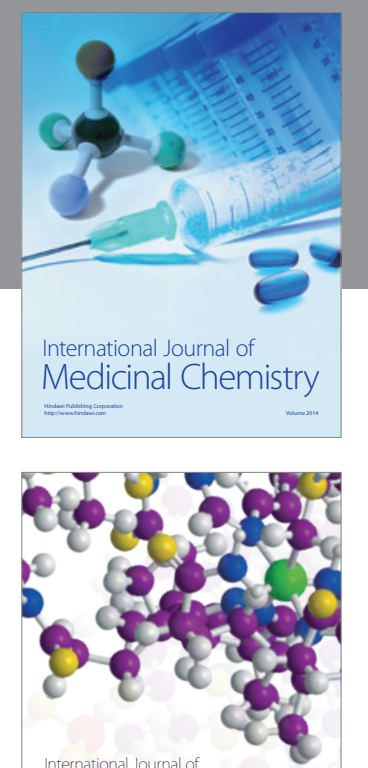

\section{Carbohydrate} Chemistry

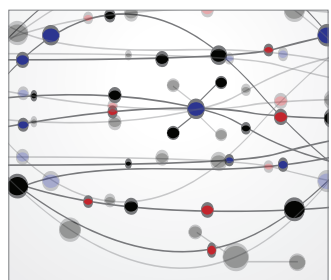

The Scientific World Journal
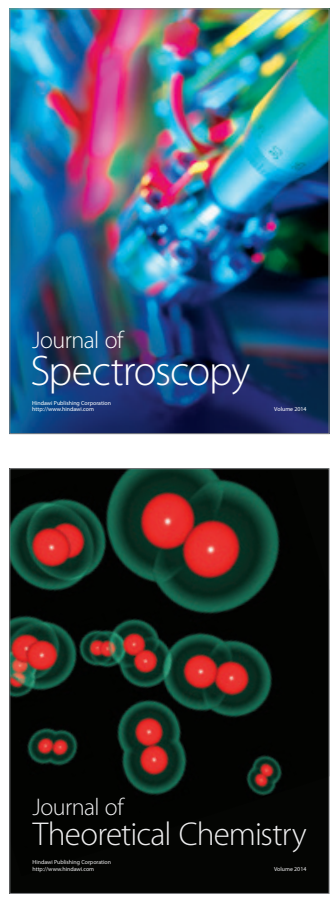
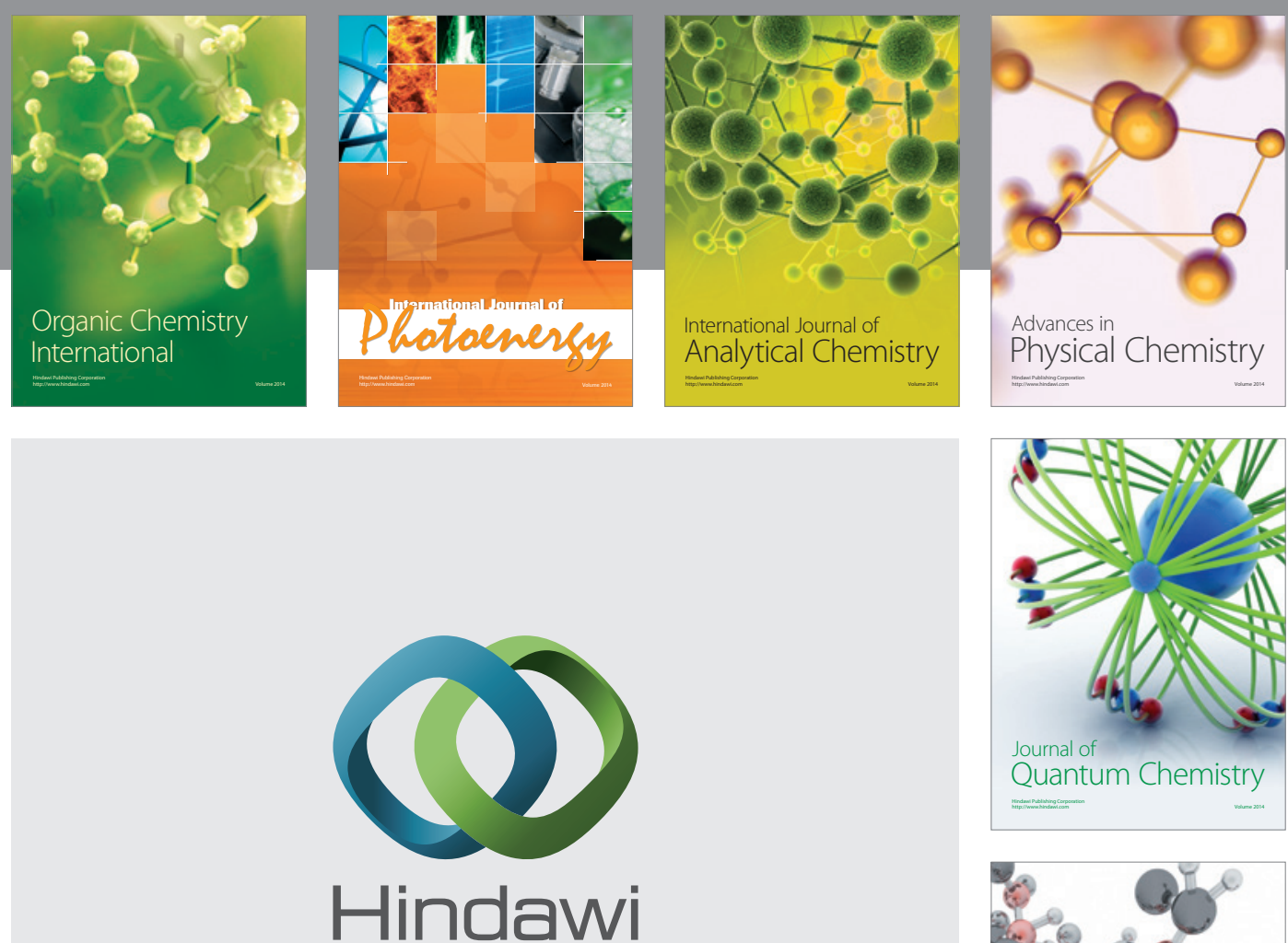

Submit your manuscripts at

http://www.hindawi.com

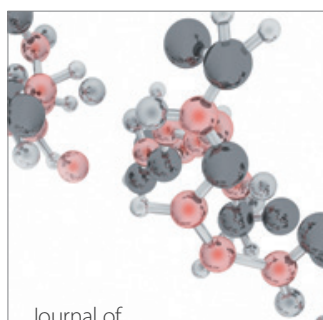

Analytical Methods

in Chemistry



Journal of

Applied Chemistry

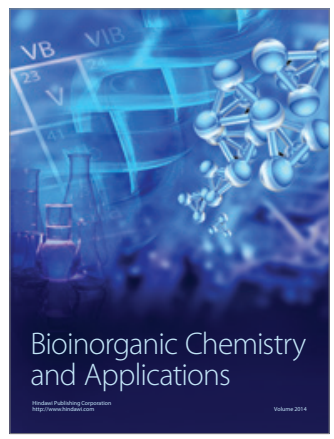

Inorganic Chemistry
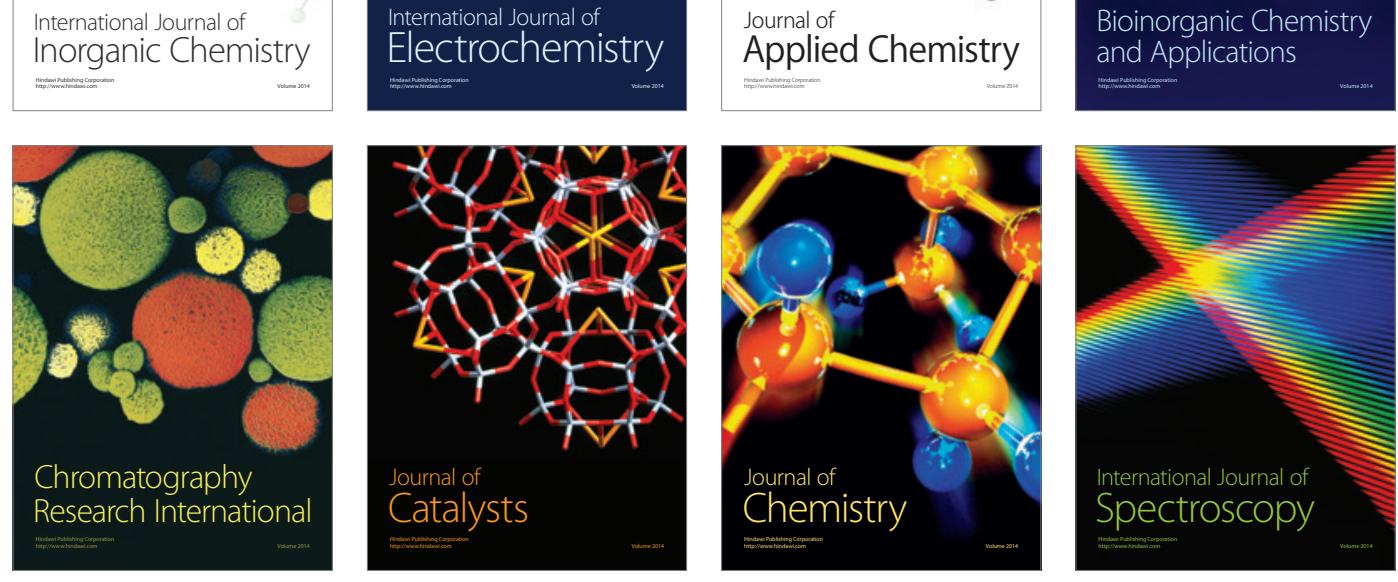